\title{
Retraction Note to: Exponential Relationship Based Approach for Predictions of Defect Density Using Optimal Module Sizes
}

\author{
Dinesh Kumar Verma ${ }^{1} \cdot$ Shishir Kumar ${ }^{1}$
}

Published online: 18 November 2019

(C) The National Academy of Sciences, India 2019

Retraction Note to: Proc. Natl. Acad. Sci., India, Sect. A Phys. Sci. (April-June 2016) 86(2):201-208 https://doi.org/10.1007/s40010-015-0261-x

The authors have retracted this article [1] because after publication they became aware that incorrect calculations in equations 2 and 3 mean that the conclusions drawn in equation 4 are incorrect. Therefore, the results are unreliable. Both the authors agree to this retraction.
The original article can be found online at https://doi.org/10.1007/s40010-015-0261-x.

\section{Shishir Kumar}

dr.shishir@yahoo.com

Dinesh Kumar Verma

dinesh.hpp@gmail.com

1 Department of Computer Science, Jaypee University of Engineering and Technology, Guna, (MP), India

\section{Reference}

1. Verma DK, Kumar S (2016) Proc. Natl. Acad. Sci. India, Sect. A Phys. Sci. 86:201. https://doi.org/10.1007/s40010-015-0261-x

Publisher's Note Springer Nature remains neutral with regard to jurisdictional claims in published maps and institutional affiliations. 